Dr Dragoslav Ugarak, pukovnik, dipl. inž. Tehnički opitni centar,
Beograd

\section{OCENA DALJINE CILJA U TOKU PRAĆENJA} VIDEO SENZORIMA

UDC: $621.397: 623.4 .023 .4$

Rezime:

U radu su opisani kinematski modeli estimacije daljine cilja, dobijene obradom video snimaka u toku praćenja. Analizirani su uticaji šuma procesa na veličinu grešaka estimacije daljine i predložen je metod adaptacije modela, podešavanjem nivoa šuma procesa.

Ključne reči: video senzori, estimacija daljine cilja, kinematski modeli, Kalmanov filter, adaptacija modela na šum procesa.

\title{
TARGET RANGE ETIMATION BASED ON VIDEO SENSOR
} TRACKING

Summary:

This paper specifies kinematic models of target range estimation based on analyzing video frames during the tracking. The influences of process noise on range estimation accuracy are analyzed, and adaptive estimation method by noise level adjustment is nominated.

Key words: video sensors, target range estimation, estimation for kinematic models, Kalman filter, adaptive estimation, noise level adjustment.

\section{Uvod}

Pozicija cilja u prostoru definisana je njegovim pravouglim ili sfernim koordinatama u toku vremena. Koordinate cilja određuju se na osnovu očitavanja parametara sa senzora u toku njegovog praćenja. Najčešće korišćeni senzori za praćenje ciljeva su: nišanski radar, laserski daljinomer, televizijska i termovizijska kamera. Radar i laser su aktivni senzori čije prisustvo se lakše otkriva i ometa od video senzora (TV i TTV kamere) koji rade u pasivnom režimu. Osnovni nedostatak video sistema je velika zavisnost daljine efikasnog praćenja cilja od meteoroloških uslova, ali se mogu efikasno koristiti na bliskim i srednjim daljinama. Video uređaji u nišanskim sistemima služe za vizuelno otkrivanje i praćenje ciljeva po ugaonim koordinatama. Problem određivanja daljine cilja, bez upotrebe aktivnih senzora, može se rešiti na osnovu poznavanja dimenzija cilja metodama projektivne geometrije. Za uspešno praćenje cilja odlučujući značaj ima tačnost određivanja koordinata cilja. Merenja koordinata cilja opterećena su šumovima i greškama, pa je potrebno izvršiti uravnavanje (filtriranje) merenih podataka radi dobijanja valjane ocene pozicije cilja $u$ toku praćenja. Da bi se ocenjivanje pozicije cilja izvršilo dovoljno kvalitetno, potrebno je da merenja budu izvedena sa 
određenom tačnosti i učestanosti i da su poznate statističke karakteristike grešaka i šumova merenja. U radu je opisan postupak merenja pozicije cilja primenom video senzora i matematički modeli za obradu podataka merenja radi dobijanja optimalnih ocena pozicije cilja $\mathrm{u}$ toku praćenja.

\section{Senzori za praćenje cilja}

Senzori za praćenje ciljeva su uređaji namenjeni da izvrše transformaciju energije elektromagnetnih talasa, koji nose informaciju o cilju, u električne signale koji treba da omoguće detekciju, prepoznavanje i identifikaciju cilja i određivanje njegovih koordinata $i$ orijentacije $u$ prostoru. Daljom obradom ovih informacija u računarima SUV-a, pomoću pogodnih algoritama, formiraju se signali upravljanja.

Senzorski podsistem za prikupljanje i obradu informacija o cilju podrazumeva par senzorski uređaj - procesor (slika 1). Senzorski uređaj obezbeđuje transformaciju elektromagnetnog zračenja koje nosi informaciju o cilju u električne signale, a procesorski uređaj vrši detekciju, prepoznavanje i identifikaciju cilja. Pod detekcijom cilja podrazumeva se utvrdivanje pri-

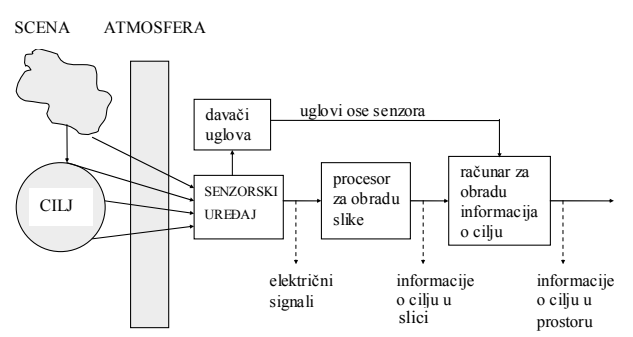

Sl. 1 - Blok-šema senzorskog podsistema za praćenje cilja sustva cilja u vidnom polju senzora. Prepoznavanje je utvrđivanje vrste cilja (na primer - avion, helikopter, bespilotna letelica, raketa, ptica), a identifikacija mogućnost utvrđivanja tipa cilja u okviru utvrđene vrste (na primer, tip aviona i slično).

Kod uređaja za automatsko praćenje ciljeva u vazdušnom prostoru senzorski podsistem obezbeđuje informacije o ugaonoj poziciji cilja u odnosu na osu senzora i daljini do cilja. Pri tome, davači uglova uređaja za praćenje cilja mere uglove azimuta i elevacije ose senzora.

Zahvaljujući svojim poznatim svojstvima televizijski i termovizijski uređaji našli su široku primenu u sistemima za izviđanje, osmatranje i praćenje ciljeva. Kompatibilnost formata termovizijske slike sa standardnim televizijskim formatom omogućava primenu jedinstvenog procesa obrade slike i simultanu obradu slike sa televizijskog i termovizijskog senzora. Njihova komplementarna primena u multisenzorskim sistemima bitno je povećala ukupne mogućnosti primene optoelektronskih nišanskih sistema, danju i noću. Zahvaljujući pasivnom režimu rada znatno je povećana otpornost na ometanje nišanskih sistema. Optoelektronski nišanski sistemi mogu se samostalno koristiti u sistemima PVO na bliskim i srednjim daljinama, a poseban značaj imaju u odbrani od niskoletećih ciljeva.

\section{Merenje daljine cilja na osnovu video snimaka}

Za određivanje daljine cilja na osnovu video snimaka koriste se metode perspektivne projektivne geometrije, pri čemu je potrebno poznavati prirodnu veli- 
činu cilja. Pri tome ce biti korišćena metoda lokacije trougla poznatih dužina strana opisana u [2].

Metoda lokacije trougla poznatih dužina strana može poslužiti za određivanje lokacije cilja na kojem se mogu uočiti tri tačke čija su međusobna rastojanja poznata. To su obično vrh, rep i krajevi krila letelice koja se prati i čiji tip i dimenzije su poznati. U [2] je obrađena putanja aviona G2, snimljena ,sky track“ teodolitima, koja predstavlja let sa manevrom propinjanja u vertikalnoj ravni.

Za potrebe određivanja daljine cilja sa snimaka TV kamere izvršeno je očitavanje koordinata vrha, dna i vrhova krila aviona u ravni snimka. Određivanje daljine cilja na osnovu poznavanja veličine cilja i koordinata karakterističnih tačaka u ravni snimka (dna, vrha i krajeva krila) izvršeno je metodom lokacije trougla poznatih dužina stranica tako što su formirana četiri trougla i za svaki od njih određena je daljina. Konačna vrednost daljine cilja dobijena je usrednjavanjem vrednosti dobijenih za četiri uočena trougla (slika 2). Kao što se može videti, daljina određena obradom snimaka osciluje oko njene stvarne vrednosti, što je posledica slučajnih grešaka merenja. Odstupanja daljine od njene stvarne vrednosti veća su na većim daljinama, zato što je lik cilja tada sitniji a time je i relativna greška merenja veća. Srednja greška određivanja daljine na rastojanju od 5 do $2,5 \mathrm{~km}$ kreće se oko $50 \mathrm{~m}$, a na manjim rastojanjima naglo pada do vrednosti oko $10 \mathrm{~m}$, odnosno do veličine realnog cilja. Vrednosti greške određivanja daljine cilja obradom video snimaka ukazuju na potrebu filtriranja dobijenih podataka.
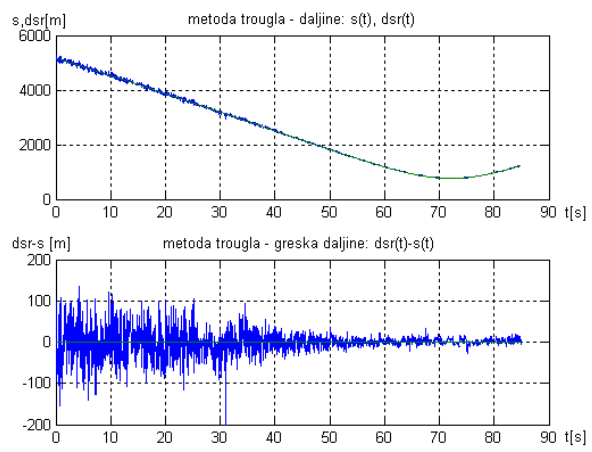

Sl. 2 - Daljina cilja određena sa snimaka TV kamere

Kvalitet podataka dobijenih obradom snimaka cilja prvenstveno zavisi od kvaliteta i rezolucije slike, odnosno od uticaja šuma u video slici i grešaka kvantizacije video signala.

\section{Estimacija daljine cilja}

Iskustva sa senzorskih uređaja za praćenje ciljeva ukazuju na to da svestranost Kalmanovog filtera čini njegovu primenu gotovo obaveznom u problemima kada nedostaju podaci, sa promenljivim statistikama šumova merenja ili pri praćenju manevrišućih ciljeva sa promenljivim dinamičkim mogućnostima. Posebno je pogodna primena sofisticiranih metoda Kalmanovog filtera na probleme praćenja visoko manevrišućih ciljeva $[3,4,5]$.

Izbor koordinata praćenja zavisi od primene [3]. Uopšte, sistemi koji koriste više fizički razdvojenih senzora treba da koriste Kartezijeve koordinate. Sferne koordinate su povoljnije za sisteme sa jednim senzorom ili sa više zajedno lociranih senzora. Upotreba sfernih koordinata olakšava razdvajanje filtera po koordinatama, što dovodi do znatnog smanjenja računanja. Razdvojeni filteri daljine $\mathrm{i}$ 
uglova sa dva stanja primenjuju se radi uravnavanja podataka merenja. Kada se meri samo pozicija uglavnom se koriste filteri sa dva stanja - pozicija i brzina. Upotreba ubrzanja kao veličine stanja generalno se zahteva ako se meri brzina, kao kod radarske radijalne brzine ili ugaone brzine praćenja. Radi predikcije kretanja cilja koristi se filter sa Kartezijevim koordinatama i devet veličina stanja.

Ovde će biti primenjen Kalmanov filter za estimaciju daljine cilja. Pošto se opservacije cilja vrše u diskretnim trenucima vremena, potrebno je da se u estimatoru koriste diskretni modeli sistema. U mnogim aplikacijama koristi se isti model za svaku koordinatu, pod pretpostavkom da se kretanje duž svake koordinate može razdvojiti od drugih koordinata. Šumovi uvedeni za različite koordinate su, po pretpostavci, uzajamno nezavisni sa moguće različitim varijansama.

Široko korišćeni modeli su kinematski modeli izvedeni iz prostih jednačina kretanja sa konstantnom brzinom i konstantnim ubrzanjem [4, 5]. Diskretna dinamička jednačina sistema je:

$x(k+1)=F x(k)+\Gamma v(k)$

gde je: $F$ matrica prelaza, $\Gamma$ pojačanje šuma dato kao vektor dimenzije $\mathrm{n}_{\mathrm{x}}$, a $\mathrm{v}(\mathrm{k})$ skalarna veličina šuma procesa, bela sekvenca nulte sredine sa kovarijansom:

$$
\begin{aligned}
& E\left[\left((\Gamma(k) v(k))(\Gamma(k) v(k))^{T}\right]=\right. \\
& =\Gamma(k) Q(k) \Gamma(k)^{T}
\end{aligned}
$$

Uvodi se pretpostavka da za vreme svakog perioda uzorkovanja dužine $\mathrm{T}$ model drugog reda ima konstantno ubr- zanje, a da se u modelu trećeg reda ubrzanje uvećava sa sekvencom belog šuma:

$$
\bar{v}(t)=v(k), \quad t \in[k T,(k+1) T]
$$

To ubrzanje je intervalno periodično konstantno ubrzanje koje je nekorelisano od perioda do perioda. Jasno je da gornja pretpostavka važi za dati period uzorkovanja $T_{1}$, ali ne mora da važi i za neki drugi period $T_{2}$ (osim za celobrojni umnožak od $\mathrm{T}_{1}$ ). Pretpostavka zasnovana na modelu periodično konstantnog ubrzanja, kao belog šuma procesa, nije potpuno tačna, nego samo aproksimativno, ali u praksi daje dobre rezultate [4].

Diskretna jednačina merenja, kada su dostupna samo merenja pozicije, data je formulom:

$z(k)=H(k) x(k)+w(k), \mathrm{k}=0,1,2, \ldots$

Ovde je za modele ubrzanja, kao belog šuma drugog i trećeg reda, matrica merenja data sa:

$\mathrm{H}\left[\begin{array}{lll}1 & 0\end{array}\right]$ ili $\mathrm{H}\left[\begin{array}{lll}1 & 0 & 0\end{array}\right]$

Autokorelaciona funkcija šumova merenja je:

$E\left[\left(w(k) w(k)^{T}\right]=R(k)\right.$

\section{Diskretni model približno konstantne brzine}

To je model drugog reda u kojem šum procesa $\mathrm{v}(\mathrm{k})$ predstavlja konstantno ubrzanje u toku k-tog perioda uzorkovanja dužine $\mathrm{T}$. Uvećanje brzine u toku tog perioda je v(k)T, dok je uticaj tog ubrzanja na poziciju izražen $\mathrm{sa} v(\mathrm{k}) \mathrm{T}^{2} / 2$. 
Jednačina stanja za model sa periodično konstantnim ubrzanjem drugog reda data je relacijom (1), gde je $\mathrm{v}(\mathrm{k})$ beli šum procesa sa nultom sredinom. Stanje modela predstavlja dvodimenzionalni vektor:

$x=\left(\begin{array}{l}x_{1} \\ x_{2}\end{array}\right)=\left(\begin{array}{l}d \\ \dot{d}\end{array}\right)$

Jednačine promene stanja biće:

$$
\begin{aligned}
& x_{1}(k+1)=x_{1}(k)+x_{2}(k) T+v(k) T^{2} / 2 \\
& x_{2}(k+1)=x_{2}(k)+v(k) T
\end{aligned}
$$

Jednačina stanja u vektorskom obli$\mathrm{ku}$ određena je matricama sistema F i G. Tranziciona matrica sistema dobija se $\mathrm{u}$ obliku:

$$
F=\left[\begin{array}{ll}
1 & T \\
0 & 1
\end{array}\right]
$$

Vektor pojačanja skalarnog šuma procesa iznosi:

$\Gamma=\left[\begin{array}{c}T^{2} / 2 \\ T\end{array}\right]$

Kovarijansa šuma procesa uvećanog sa vektorom pojačanja iznosi:

$$
Q=\Gamma \sigma_{v}^{2} \Gamma^{T}=\sigma_{v}^{2}\left[\begin{array}{ll}
\frac{1}{4} T^{4} & \frac{1}{2} T^{3} \\
\frac{1}{2} T^{3} & T^{2}
\end{array}\right]
$$

Ovde je $\sigma_{\mathrm{v}}{ }^{2}$ varijansa skalarnog šuma procesa v(k). Fizička dimenzija za šum v i njegovo standardno odstupanje $\sigma_{\mathrm{v}}$ je ista kao i za ubrzanje $\left[\mathrm{m} / \mathrm{s}^{2}\right]$. Promene brzine $\mathrm{u}$ toku perioda $\mathrm{T}$ su reda veličine:

$$
\Delta V=\sqrt{Q_{22}}=\sqrt{T^{2} \sigma_{v}^{2}}=T \sigma_{v}[\mathrm{~m} / \mathrm{s}]
$$

Ova činjenica može poslužiti da se odredi veličina šuma procesa. Za ovaj model standardno odstupanje šuma procesa mora biti reda veličine ubrzanja:

$\sigma_{v}=\frac{\Delta V}{T}=a \quad\left[m / s^{2}\right]$

Izborom male vrednosti za standardno odstupanje šuma procesa promena brzine biće mala u odnosu na aktuelnu brzinu, pa se tada dobija model približno konstantne brzine (NCV).

Da bi se izloženi model sistema primenio za sintezu Kalmanovog filtera za estimaciju daljine cilja merenu sa video snimaka u toku praćenja, potrebno je odrediti varijanse šuma merenja i šuma modela.

Varijansa šuma merenja daljine cilja sa video snimaka određena je ranije u obliku formule za standardno odstupanje daljine. Standardno odstupanje daljine cilja može se odrediti na osnovu standardnog odstupanja veličine lika cilja i prema [2] iznosi:

$$
\sigma_{d}=\frac{d^{2}}{f L} \sigma_{l}
$$

gde je: d daljina cilja, $f$ fokusna daljina izražena u pikselima, koja za upotrebljenu TV kameru iznosi 40000 piksela, L je dimanzija cilja koja za avion G2 iznosi $\mathrm{L}=10 \mathrm{~m}$, a $\sigma_{1}=1$ piksel je standardna greška merenja dimenzije cilja na video snimcima. 
Smenom ovih vrednosti u jednačinu (14) dobija se da varijansa šuma merenja daljine sa video snimaka iznosi:

$$
R(k)=\left(\frac{d(k)^{2}}{400000}\right)^{2} \quad\left[m^{2}\right]
$$

Radi određivanja varijanse šuma procesa $\sigma_{\mathrm{v}}$ potrebno je pretpostaviti veličinu ubrzanja promene daljine cilja, saglasno relaciji (13). Za ilustraciju uticaja veličine ubrzanja promene daljine cilja na kvalitet estimacije daljine urađen je primer sa tri vrednosti ubrzanja, odnosno standardnog odstupanja šuma procesa, $\mathrm{i}$ to: $\sigma_{\mathrm{v}}=1, \sigma_{\mathrm{v}}=5 \mathrm{i}$ $\sigma_{\mathrm{v}}=10 \mathrm{~m} / \mathrm{s}^{2}$. Dobijene vrednosti greške estimacije u odnosu na daljinu određenu ,sky track" teodolitima (s-dkal) i ubrzanja promene daljine (asr), date su na slici 3.
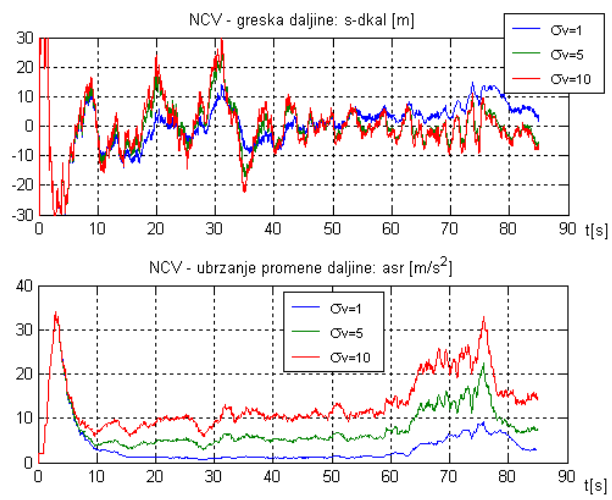

Sl. 3 - Estimacija daljine cilja prema modelu približno konstantne brzine (NCV)

Sa dijagrama se može videti da je u početnom delu putanje greška određivanja daljine manja kod modela sa manjim standardnim odstupanjem $\sigma_{v}$, a da se sa približavanjem cilja dobija manja greška kod modela sa većim standardnim odstupanjem $\sigma_{\mathrm{v}}$. Srednja vrednost ubrzanja na poslednjem dijagramu određena je usrednjavanjem $u$ prozoru od $n=50$ tačaka, po formuli: $a s r=\frac{1}{n} \sum_{k=1}^{n} \frac{\operatorname{Vkal}(k)-\operatorname{Vkal}(k-1)}{T}$

Dobijeni rezultati pokazuju da srednje ubrzanje menja vrednost saglasno promeni brzine kretanja cilja.

Može se zaključiti da tačnost estimacije veoma zavisi od veličine varijanse šuma procesa, odnosno od pretpostavljene vrednosti ubrzanja promene daljine. Štaviše, pokazuje se da to ubrzanje ima promenljiv karakter, što je potrebno uzeti u obzir pri modeliranju filtera. To se rešava adaptacijom modela estimacije na promenljivi šum procesa.

\section{Diskretni model približno konstantnog ubrzanja}

To je model trećeg reda $\mathrm{u}$ kojem šum procesa $\mathrm{v}(\mathrm{k})$ predstavlja uvećanje ubrzanja u toku k-tog perioda. Pod pretpostavkom da je šum bela sekvenca sa nultom sredinom, ubrzanje je diskretni Wienerov proces. Vektor stanja u ovom slučaju je:

$x=\left(\begin{array}{l}x_{1} \\ x_{2} \\ x_{3}\end{array}\right)=\left(\begin{array}{l}d \\ \dot{d} \\ \ddot{d}\end{array}\right)$

Jednačine stanja ovog modela su:

$$
\begin{aligned}
& x_{1}(k+1)=x_{1}(k)+x_{2}(k) T+x_{3}(k) T^{2} \\
& / 2+v(k) T^{2} / 2 \\
& x_{2}(k+1)=x_{2}(k)+x_{3}(k) T+v(k) T \\
& x_{3}(k+1)=x_{3}(k)+v(k)
\end{aligned}
$$


Tranziciona matrica sistema dobija se u obliku:

$$
F=\left[\begin{array}{ccc}
1 & T & T^{2} / 2 \\
0 & 1 & T \\
0 & 0 & 1
\end{array}\right]
$$

Vektor pojačanja skalarnog šuma procesa iznosi:

$\Gamma=\left[\begin{array}{c}T^{2} / 2 \\ T \\ 1\end{array}\right]$

Kovarijansa šuma procesa uvećanog sa vektorom pojačanja iznosi:

$$
Q=\Gamma \sigma_{v}^{2} \Gamma^{T}=\sigma_{v}^{2}\left[\begin{array}{ccc}
\frac{1}{4} T^{4} & \frac{1}{2} T^{3} & \frac{1}{2} T^{2} \\
\frac{1}{2} T^{3} & T^{2} & T \\
\frac{1}{2} T^{2} & T & 1
\end{array}\right]
$$

Ovde je $\sigma_{\mathrm{v}}^{2}$ varijansa skalarnog šuma procesa $\mathrm{v}(\mathrm{k})$. Fizička dimenzija za šum v i njegovo standardno odstupanje $\sigma_{\mathrm{v}}$ je ista kao i za ubrzanje $\left[\mathrm{m} / \mathrm{s}^{2}\right]$. Promena ubrzanja $\mathrm{u}$ toku perioda $\mathrm{T}$ je reda veličine:

$$
\Delta a=\sqrt{Q_{33}}=\sqrt{\sigma_{v}^{2}}=\sigma_{v} \quad\left[\mathrm{~m} / \mathrm{s}^{2}\right]
$$

Za ovaj model standardno odstupanje šuma procesa treba da bude reda veličine maksimalne promene ubrzanja $\Delta \mathrm{a} u$ periodu uzorkovanja. Izborom malog intenziteta standardnog odstupanja šuma procesa promena ubrzanja biće mala $\mathrm{u}$ odnosu na aktuelno ubrzanje, pa se tada dobija model približno konstantnog ubrzanja (NCA).

Da bi se izloženi model sistema primenio za sintezu Kalmanovog filtera za estimaciju daljine cilja merenu sa video snimaka u toku praćenja potrebno je, kao i u prethodnom slučaju, odrediti varijanse šuma merenja i šuma procesa. Varijansa šuma merenja daljine cilja $\mathrm{R}(\mathrm{k})$ sa video snimaka ranije je određena formulom (15).

Radi određivanja varijanse šuma procesa Q potrebno je pretpostaviti veličinu ubrzanja promene daljine cilja, saglasno relaciji (22). Za ilustraciju uticaja promene ubrzanja promene daljine cilja na kvalitet estimacije daljine urađen je primer sa tri vrednosti promene ubrzanja, odnosno standardnog odstupanja šuma procesa, $i$ to: $\Delta \mathrm{a}=0,001, \Delta \mathrm{a}=0,01$ i $\Delta \mathrm{a}=0,1 \mathrm{~m} / \mathrm{s}^{2}$. Dobijene vrednosti greške estimacije daljine (s-dkal), u odnosu na daljinu (s) određenu ,sky track“ teodolitima i promene ubrzanja ( $\Delta$ asr) prikazane su na slici 4.

Sa dijagrama se može videti da je u početnom delu putanje greška određivanja daljine manja kod modela sa manjom promenom ubrzanja $\Delta \mathrm{a}$, a da se sa približavanjem cilja dobija manja greška kod modela sa većom promenom ubrzanja. Srednja vrednost promene ubrzanja $\Delta$ asr na poslednjem dijagramu određena je usrednjavanjem u prozoru od $n=50$ tačaka, po formuli:

$$
\Delta a s r=\frac{1}{n} \sum_{k=1}^{n}\left[a_{k a l}(k)-a_{k a l}(k-1)\right]
$$



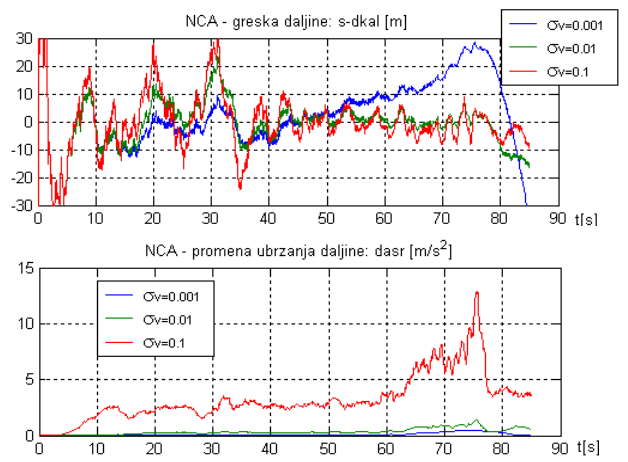

Sl. 4 - Estimacija daljine cilja prema modelu približno konstantnog ubrzanja (NCA)

Dobijeni rezultati pokazuju da promena ubrzanja zadržava zadatu vrednost u početnom delu putanje i da je sa približavanjem cilju uvećava proporcionalno dinamici kretanja cilja, kao što se može videti sa zadnjeg dijagrama na slici 4 .

Može se zaključiti da tačnost estimacije daljine i za ovaj model veoma zavisi od veličine varijanse šuma procesa, odnosno od pretpostavljene vrednosti promene ubrzanja daljine. To znači da je potrebno izvršiti adaptaciju modela estimacije na promenljivi šum procesa u toku praćenja cilja.

\section{Podešavanje nivoa šuma procesa}

Za praćenje cilja koristi se model $\mathrm{u}$ kojem je pretpostavljen određeni nizak nivo šuma procesa. Nivo šuma određen je pomoću njegove varijanse. Ako cilj počne da menja način kretanja dolazi do promene ubrazanja koje je modelisano sa šumom procesa. To znači da se pri pojavi manevra u modelu cilja mora menjati intenzitet šuma procesa da bi se model prilagodio novim vrednostima ubrzanja cilja.
Kod estimacije daljine cilja, čak i kada se cilj kreće konstantnom brzinom a približava video senzoru, dolazi do promene radijalne brzine $u$ odnosu na uređaj za praćenje, što se može smatrati pojavom manevra. Praktično, to znači da se sa približavanjem cilja prag manevra neprestano menja. Zato se u svrhu adaptacije estimatora u toku praćenja cilja predlaže stalno određivanje ubrzanja promene daljine cilja radi prilagođavanja nivoa šuma procesa.

$\mathrm{Na}$ osnovu dijagrama grešaka estimacije daljine (s-dkal) na slikama 3 i 4 zaključuje se da je potrebno uvesti promenljivu vrednost za standardno odstupanje suma procesa $\sigma_{v}$, saglasno promenama ubrzanja (asr), odnosno priraštaja ubrzanja ( $\Delta$ asr) u toku praćenja cilja, kako bi greška određivanja daljine u početnom delu putanje odgovarala modelu sa manjim $\sigma_{v}$, a u završnom delu sa većim $\sigma_{v}$. To se rešava adaptacijom modela estimacije na promenljivo ubrzanje.

Kod modela sa približno konstantnom brzinom (NCV), nakon inicijalizacije Kalmanovog filtera, uz pretpostavku nižeg nivoa varijanse šuma procesa $\sigma_{\mathrm{v}}{ }^{2}=1$, izračunavaju se srednje vrednosti ubrzanja promene daljine cilja asr $=\Delta \mathrm{V} / \mathrm{T}$, u kliznom prozoru, po formuli (16). Posle izračunavanja prve vrednosti asr uvodi se nova vrednost za varijansu šuma po formuli:

$\sigma_{v}^{2}=a s r$

Dijagram greške određivanja daljine nakon izvršene adaptacije estimatora po modelu NCV prikazan je na slici 5. Radi poređenja rezultata sa estimatorom bez adaptacije po istom modelu, prikazan je 
dijagram greške određivanja daljine za adaptivni (ANCV) i neadaptivni (NCV) model. Kao što se može videti, nakon uvođenja adaptacije rezultati estimacije su poboljšani u smislu smanjivanja greške određivanja daljine cilja.
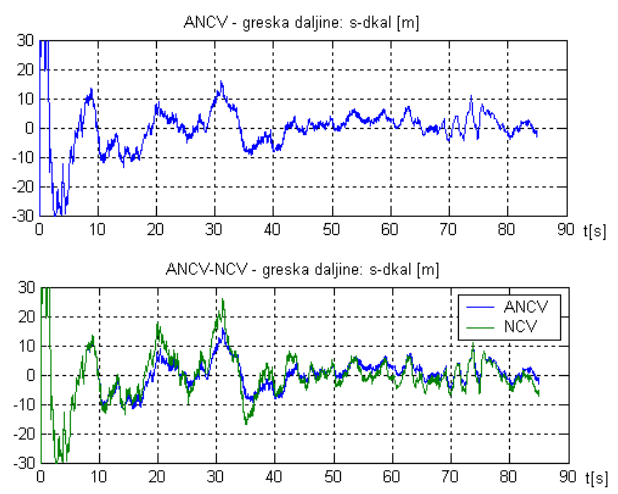

\section{Sl. 5 - Greške daljina za ANCV i NCV modele}

Kod modela sa približno konstantnim ubrzanjem (NCA), nakon inicijalizacije Kalmanovog filtera uz pretpostavku nižeg nivoa varijanse šuma procesa $\sigma_{\mathrm{v}}{ }^{2}=0,0001$, izračunavaju se srednje vrednosti promene ubrzanja $\Delta$ asr, u kliznom prozoru, po formuli (23). Posle izračunavanja prve vrednosti asr uvodi se nova vrednost za varijansu šuma po formuli:

$\sigma_{v}^{2}=\Delta a s r T$

Rad estimatora po NCA modelu nakon izvršene estimacije (ANCA) prikazan je na slici 6 u vidu dijagrama greške određivanja daljine i dijagrama grešaka daljine cilja za adaptivni i neadaptivni NCA model. Vidi se da je nakon adaptacije određivanje daljine znatno popravljeno, naročito u početnom delu putanje, gde su greške i bile najveće.
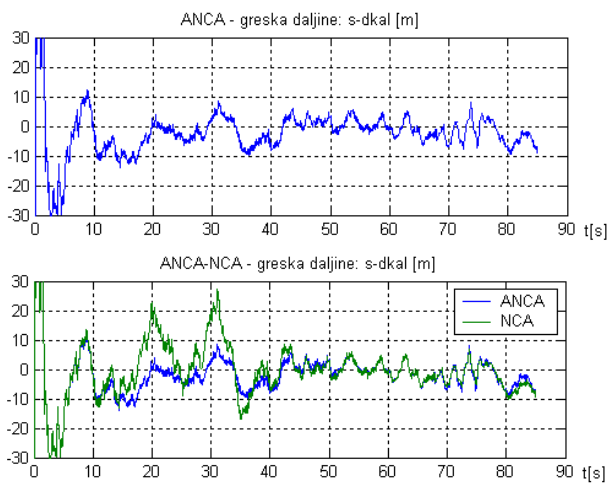

Sl. 6 - Greške daljina za ANCA i NCA modele

Poređenjem rezultata estimacije adaptivnih modela sa približno konstantnom brzinom i približno konstantnim ubrzanjem može se zaključiti da u ovom slučaju kretanja cilja oba modela podjednako dobro estimiraju daljinu cilja.

\section{Zaključak}

U radu je izvršena sinteza estimatora daljine cilja u vidu adaptivnog Kalmanovog filtera za dva modela promene daljine, sa približno konstantnom brzinom (ANCV) i približno konstantnim ubrzanjem (ANCA). Konačni rezultati pokazuju da se dobijena daljina cilja veličine 10 $\mathrm{m}$ na daljini od $5 \mathrm{~km}$, sa video sistemom fokusne daljine $750 \mathrm{~mm}$, određuje sa tačnošću $\pm 10 \mathrm{~m}$. To znači da su dobijene vrednosti daljine cilja potpuno upotrebljive za određivanje pozicije cilja u SUV PVO, čak se može reći da su u klasi tačnosti radarskih (5 do $10 \mathrm{~m}$ ) i laserskih (2 do $5 \mathrm{~m}$ ) daljinomera. Tačnost određivanja daljine cilja obrnuto je srazmerna fokusnoj daljini video sistema. Znači da će se sa povećavanjem fokusne daljine video sistema povećati tačnost određivanja daljine 
udaljenih ciljeva. U datom primeru, povećavanjem fokusne daljine na $1500 \mathrm{~mm}$, što postoji kao mogućnost razmatrane kamere, procenjuje se da će tačnost određivanja daljine cilja veličine $10 \mathrm{~m}$ na daljini od 8 do $10 \mathrm{~km}$ iznositi $10 \mathrm{~m}$. To ukazuje na važan zaključak da je obradom video snimaka cilja moguće dovoljno tačno određivanje daljine aktuelnih letećih ciljeva na zahtevanim daljinama dejstva SUV PVO artiljerijskim oruđima. Primena ove metode moguća je uz upotrebu savremenih digitalnih video kamera i računarskih sistema velikog kapaciteta i brzine obrade podataka. Oni mogu u realnom vremenu da obrade sve podatke sa video slike i izvrše estimaciju sfernih koordinata cilja, azimuta, elevacije i daljine, u periodu formiranja video slike, koji se dalje koriste za predikciju pozicije cilja radi odredivanja elemenata gađanja.

U radu je izložena osnovna primena nove metode za potrebe praćenja cilja $u$ pasivnom režimu rada senzora, koji se teško otkriva i ometa. Izložena metoda ima i ograničenja zbog zahteva za apriornim poznavanjem veličine cilja, senzorima viso- kog kvaliteta video snimaka sa velikim uvećanjem i računarima velike brzine i kapaciteta za obradu velikog broja podataka u realnom vremenu. Ova ograničenja se lako mogu prevazići, pa se preporučuje primena ove metode u SUV PVO samostalno ili kao obavezna dopuna uz postojeće načine određivanja pozicije cilja pomoću aktivnih senzora, radara ili lasera.

Nova metoda za određivanje i estimaciju daljine cilja, postavljena na osnovu obrade video snimaka, može imati veoma široku primenu, kako vojnu, tako i civilnu. Značajno mesto može imati u sistemima za navigaciju pokretnih objekata ili u automatizaciji industrijske proizvodnje i slično.

\section{Literatura:}

[1] Ugarak, D.; Milinović, M.: Error and noise analyses and their influence on the air target tracking and coordinates estimation, Scientific Tehnical Review, Vol LIII, No.1, 2003.

[2] Ugarak, D.: Određivanje daljine cilja pomoću video senzora $i$ analiza uticaja grešaka i šuma merenja, OTEH Vojna akademija, Beograd, 2005.

[3] Blackman, S.: Design and Analysis of Modern Tracking Systems, Norwood, MA:Arteach House, 1999.

[4] Bar-Shalom, Y.: Estimation With Applications to Tracking and Navigation, John Wily \& Sons, New York, 2001.

[5] Zarchan, P.; Musoff, H.: Fundamentals of Kalman Filtering: A Practical Approach, Cambridge, Massachusetts, 2000. 